\title{
Expanding the concept of social behavior to interspecific interactions
}

\author{
Rui F. Oliveira ${ }^{1,2,3}$ | Redouan Bshary ${ }^{4}$ ()
}

${ }^{1}$ Instituto Gulbenkian de Ciência, Oeiras, Portugal

${ }^{2}$ ISPA - Instituto Universitário, Lisboa,

Portugal

${ }^{3}$ Champalimaud Neuroscience

Programme, Lisboa, Portugal

${ }^{4}$ Institute of Biology, University of Neuchâtel, Neuchâtel, Switzerland

Correspondence

Rui F. Oliveira, Instituto Gulbenkian de

Ciência, Oeiras, Portugal.

Email: ruiol@ispa.pt

Funding information

Fundação para a Ciência e a Tecnologia, Grant/Award Number: UIDB/04555/2020 and PTDC/BIA-COM/30627/2017; Swiss National Science Foundation, Grant/ Award Number: 310030B_173334/1

\begin{abstract}
In pretty much any species, an individual's survival and reproduction depends crucially on the outcome of interactions with other individuals. Key interactions may take place between individuals of the same species but also between individuals belonging to different species. However, the most accepted definition of social behavior only considers interactions between conspecifics. Here, we argue that the distinction between intra- and interspecific interactions is largely artificial and hinders the integration of the historically separately developed concepts. At the ultimate level, given that the ecological landscape of organisms is composed both by interactions with conspecifics and with heterospecifics, and both types of interactions may have evolutionary consequences. Although intraspecific interactions usually have a higher impact in fitness because in most species interactions relevant for reproduction (mating, parenting) exclusively involve conspecifics, and interactions relevant for survival are more probable between conspecifics because they share the same ecological niche, hence competing for the same resources (e.g., food, shelter), there are notable exceptions in both fitness components (e.g., heterospecific mating in parthenogenic all-female species; heterospecific brood parasitism; heterospecific aggression in sympatric species that compete for shared resources). At the proximate level, behaviors and cognitive decision-making rules used to interact with other organisms may be shared between intra- and interspecific interactions, and the mechanistic differences between conspecific social behaviors used in distinct functional domains, such as mating, aggression, or parenting, can be more expressive than those found within the same functional domain between conspecific and heterospecific behavior. Therefore, there are neither fundamental conceptual (ultimate) reasons, nor key differences in mechanisms underlying behaviors involved in conspecific vs. heterospecific interactions that support the exclusion of interspecific interactions from the conceptual framework of social behavior.
\end{abstract}

\section{KEYWORDS}

heterospecific aggression, heterospecific mating, heterospecific alloparental care, heterospecific cooperation, social interactions 


\section{1 | INTRODUCTION}

The Darwinian fitness of most animals depends to a large extent on the outcome of interactions with other individuals in multiple functional domains, including resource defense (e.g., food, shelter), mating and parenting, predation, and/or predator evasion. Typically, interactions in some of these functional domains are more frequent between conspecifics (e.g., resource defense, mating, parenting) and in other domains between heterospecifics (e.g., predator-prey interactions). Historically, the animal behavior literature exclusively considers conspecific interactions as social (Székely et al., 2010), without providing any alternative term for behavior in heterospecific interactions. However, this dichotomy between intra- and interspecific interactions is largely artificial and hinders the integration of the historically separately developed concepts in both fields. In fact, the social landscape of most species in the wild includes both conspecifics and heterospecifics and the integration of both in a common conceptual framework for the study of social interactions would be beneficial. Take the example of sympatric cichlid species of the great African lakes or South American crater Lakes with overlapping breeding seasons. Multiple species, which vary in their phylogenetic relatedness, share breeding grounds densely occupied with multiple breeding heterospecific and conspecific individuals that actively defend their breeding territories and/or offspring (Barlow, 2000; McKaye, 1977). In such scenario, territorial aggression can be directed toward (1) conspecific and heterospecific resource competitors (i.e., competing for breeding territories); (2) conspecific and heterospecific brood predators; and (3) conspecific sexual competitors (i.e., competing for mates; Lehtonen et al., 2010, 2012; McKaye, 1977). Therefore, an understanding of the biology of social behavior at both ultimate (ecology, evolution) and proximate (development, physiology) in this scenario needs the integration of both conspecific and heterospecific interactions in the same conceptual framework.

The main aim of this article is to provide explicit examples in favor of a less restrictive definition of social behavior. We do not attempt to provide a new definition that includes all interspecific interaction as well, but propose that a more holistic view on interactions may improve our understanding of both ultimate and proximate causes of social behavior. Indeed, both conspecific and heterospecific interactions are characterized by the need of fine adjustment of behavioral expression as a function of the behavior of the interactant agent. Hence, they may pose similar sensory and cognitive problems that need the evolution of adaptive flexible responses to another living organism. As it stands, a meta-analysis of species discrimination in animals has shown that it is not universal and that it is dependent on the benefits and costs of responding to a conspecific vs. heterospecific that is specific to the circumstances of a given species (Ord et al., 2011). This shows that the distinction between conspecifics and heterospecifics is to some extent a human construct.

\section{A FUNCTIONAL PERSPECTIVE}

From a functional perspective, Hamilton (1964) classified a behavior as social if it has the consequence - $c$ on the actor and the consequence $b$ on the recipient. The lifetime consequences of two-player social interactions can be captured in a $2 \times 2$ matrix. $+/+$ has been termed either mutually beneficial behavior or cooperation, $-/+$ is defined as biological altruism, +/- is defined as selfishness, and -/is defined as spite (Hamilton, 1964; Lehmann \& Keller, 2006; West et al., 2007). The same $2 \times 2$ matrix can be used to describe the lifetime fitness consequences of interspecific interactions (Begon et al., 1990). A +/+ outcome has been termed mutualism, and a +/or -/+ outcome of interactions characterizes parasite-host and predator-prey interactions. Finally, a mutually negative effect on each other (-/-) has been termed competition. Hosts may be manipulated to behave altruistically $(-/+)$ toward parasites (Bakker et al., 2017); such behavior is under negative selection in hosts (and maintained due to the positive selection on manipulative strategies in parasites). Selection is expected to operate on individual strategies that differ in payoffs no matter whether an interaction partner is a conspecific or a heterospecific. Nevertheless, the strength of selection will differ depending on whether interactions are intraor interspecific (Bergstrom et al., 2003). This is because the payoff consequences of interactions are computed in a single matrix for within-species interactions (individuals of the same gene pool are in direct competition), while for interspecific interactions, each individual competes with members of its own gene pool rather than with the interaction partner. In a football analogy, a betweenspecies interaction is a 3-point game (if I win, I gain 3 points, and if I lose, I gain 0 points), whereas a within-species interaction is a 6-point game (the 3 points I loose are gained by a competitor). Regarding contexts, it is of course true that some types of interactions are almost exclusively observed among conspecifics (mating, parental care) and others between heterospecifics (predation). However, as we describe below, there are various exceptions that highlight the artificiality of the conspecific/heterospecific boundaries in the definition of social behavior.

\section{1 | Heterospecific aggression}

Direct competitive interactions are common between heterospecific organisms, and aggressive behaviors are often used in such interactions (Peiman \& Robinson, 2010). Heterospecific aggression is often related to competition for resource use when there is an overlap in the ecological niche [e.g., food: cutthroat trout, Oncorhynchus clarki vs. coho salmon, O. kisutch, Sabo \& Pauley, 1997; shelter (dens): red foxes, Vulpes vulpes vs. arctic foxes, Alopex lagopus, Tannerfeldt et al., 2002], and can be as intense and costly as conspecific aggression, therefore impacting Darwinian fitness with putative ecological and evolutionary consequences (Grether et al., 2013; Peiman \& Robinson, 2010). 

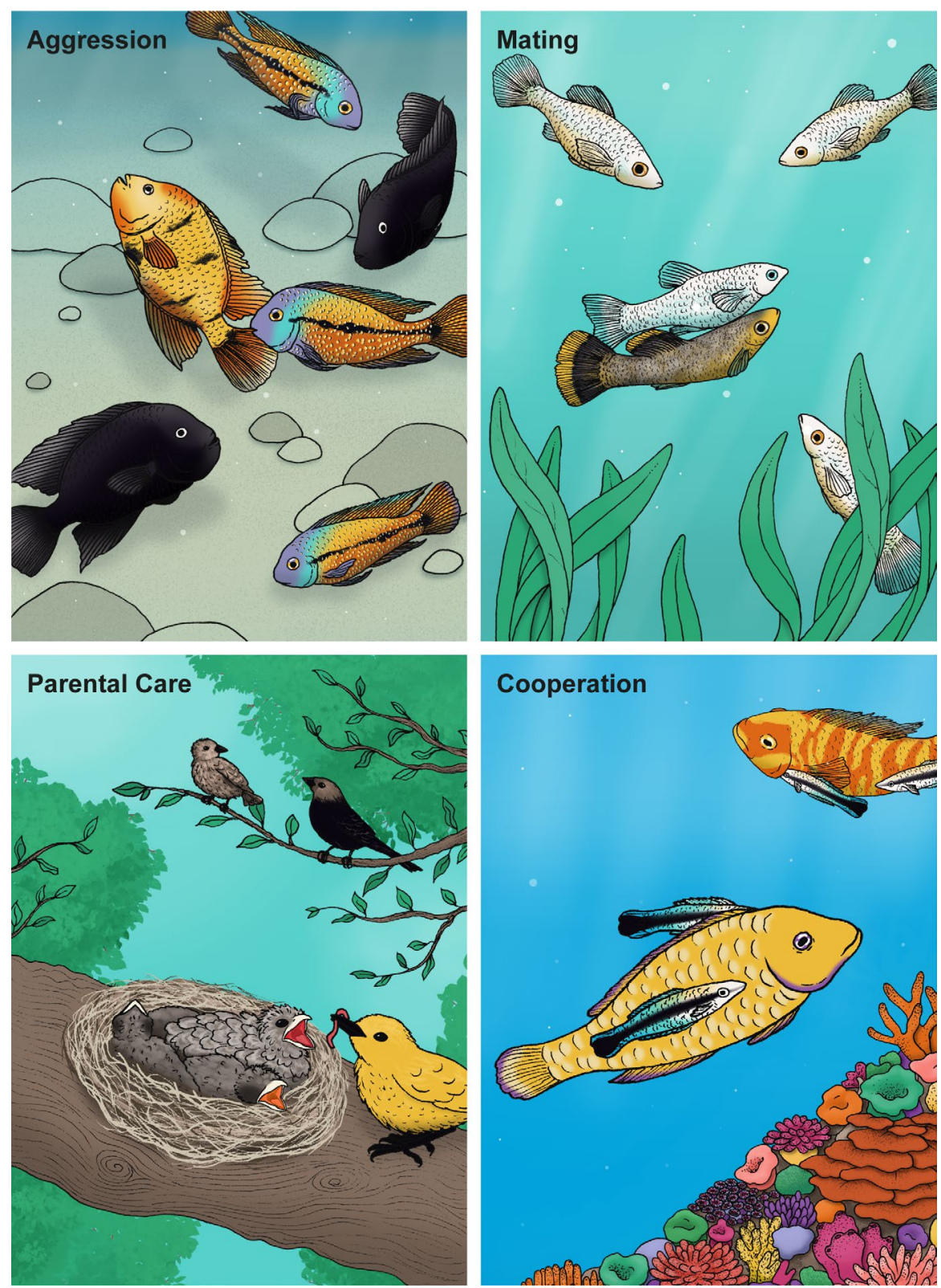

FIGURE 1 Illustrative examples of social heterospecific interactions in different functional domains: (a)

Aggression-The south American cichlid Hypsophrys nicaraguensis (yellow striped individuals) show heterospecific aggression bias toward a rarer color morph (yellow barred individual) of the sympatric cichlid Amphilophus sagittae, hence influencing the evolutionary equilibrium between color morphs (dark individuals are the alternative color morph of A. sagittae; after Lehtonen et al., 2015).

(b) Mating-Amazon mollies (Poecilia formosa, central gray individual) are an allfemale unisexual fish species that mates with heterospecific males (central colored individual), which gain a fitness benefit because of mate-choice copying decisionrules of their conspecific females (gray bystander individuals) (after Schlupp et al. 1994). (c) Parental care-Brood parasites (dark cowbirds) lay eggs in other species nests (yellow warbler), which raise their chicks; parasitic chicks have been selected for more efficient begging behavior thus outcompeting the host chicks in food provisioning by the host parents (after Davies, 2000). (d) Cooperation-Cleaner wrasse (Labroides dimidiatus, small elongated fish) remove ectoparasites from client reef fish of many diverse species (larger yellow individuals; after Bshary \& Grutter, 2006)
At the ecological level, heterospecific aggression results in niche partitioning through the regulation of the strength of the species interference leading to phenotypic displacement in traits that affect heterospecific interactions (e.g., habitat preferences, fighting ability, competitor recognition; Grether et al., 2009, 2013). In this scope it is interesting to note that the expression of heterospecific aggression can be flexible, with more aggressive responses directed toward heterospecific opponents that pose a higher threat. For example, the South American arrow cichlid (Amphilophus zaliosus) adjusts its territorial defense toward heterospecific intruders according to their breeding status (breeding individuals receive lower level of aggression than non-breeders; Thus, heterospecific interactions should also be considered as a source of selection pressure shaping plasticity of aggressive behavior (Lehtonen et al., 2010).

Heterospecific aggression can be adaptive, if it increases fitness through the acquisition of limited resources, and evolve independently of intraspecific aggression. Peiman and Robinson (2010), using a simulated intrusion test, found that heterospecific aggression was greater in sympatry than in allopatry for species where resource overlap occurred and that it was not correlated with intraspecific aggression. Moreover, they also found that aggression was higher with increased resource overlap. Interestingly, there is also evidence for heritable variation in heterospecific aggression in brook sticklebacks (Culaea inconstans), where aggressive responses toward heterospecific competitors (ninespine stickleback, Pungitius pungitius) are higher in sympatric than in allopatric populations (Peiman \& Robinson, 2007), which further supports its evolvability. Heterospecific aggression may even influence intraspecific evolutionary dynamics. In Amphilophus sagittae, a South American cichlid, a color polymorphism occurs with gold and dark morphs present in the population. 
These color morphs elicit differential heterospecific aggression from their territorial neighbors of another cichlid species (Hypsophrys nicaraguensis), which are more aggressive toward gold than dark morphs (Figure 1a). Thus, heterospecific aggression potentially contributes to the evolutionary equilibrium among these color morphs (Lehtonen et al., 2015).

Together these results support an adaptive role for heterospecific aggression. Apart from its role in competition for resources, heterospecific aggression may also act as a way to avoid hybridization (see section below), and selection for increased heterospecific aggression may also be associated with reduced costs of wasted reproductive effort on heterospecifics (Peiman \& Robinson, 2010).

\subsection{Heterospecific reproductive behavior: mating and parenting}

Even social interactions that occur in the scope of reproduction, intuitively the most obvious reason for a distinction between intra- and interspecific interactions, may occur between species. A classic example of heterospecific mating involves Amazon mollies (Poecilia formosa), an all-female unisexual fish species that reproduces through gynogenesis, which is a form of parthenogenesis that requires the presence of sperm of a male from closely related species to trigger embryogenesis without the genetic contribution of sperm DNA for the zygote (Schlupp, 2005). In this system, selection for heterospecific mating occurred in both sexes, since males of the closely related species benefit from mating with heterospecific females because of mate-choice copying decision-rules of their conspecific females (Sclupp et al., 1994; Figure 1b). Several maladaptive cases of interspecific sexual interactions have been described in the literature from a wide range of species (Groning and Hochkirch, 2008). Nevertheless, these other cases of reproductive interference may have ecological and/or evolutionary consequences, leading to the species exclusion or character displacement, and are particularly relevant in the scope of invasive species because endemic species can be threatened by sexual interactions with the new introduced species (Groning and Hochkirch, 2008). In the case of rare successful hybridization, heterospecific mating may facilitate rapid evolutionary radiations, as recently described for Lake Victoria and Lake Malawi cichlids, where ancestral hybridization provided the genetic variation that subsequently became recombined and gave rise to a flock of new species (Meier et al., 2017, 2019; Svardal et al., 2020).

Within the scope of reproductive behaviors, also parental care interactions can be observed between heterospecifics. The occurrence of brood care parasitism, in which organisms rely on others from a different species to raise their offspring, has been described in birds, insects, and one species of fish (Davies, 2000; Polacik et al., 2019; Sato, 1986). Typically, the brood parasites manipulate the behavior of the heterospecific host using brood mimicry, inducing it to express alloparental behavior toward their young (Davies, 2000; Stevens, 2013; Figure 1c). By adopting this behavior, brood parasites avoid the costs associated with parental care, such as nest building and time and energy investment in feeding the young, allowing them to increase their investment in foraging and reproduction with associated fitness benefits. Brood parasitism typically results in evolutionary arms races between brood parasites and their hosts leading to the coevolution of both species. In birds, where obligatory interspecific brood parasitism is more common, it evolved independently seven times and occurs in approximately $1 \%$ of species, and different stages of coevolution can be observed (Davies, 2000; Kilner \& Langmore, 2011; Sorenson \& Payne, 2005).

As a result of the arms race described above, both brood parasites and their hosts have evolved a set of behaviors and cognitive abilities that are clearly of the social domain. For example, female brood parasites are able to track the nesting progress of hosts and to choose nests or to time their egg laying accordingly to ensure optimal development of their young (Davies, 2011). Brood parasite females also behave secretively to approach the host nests without being noticed and evolved rapid egg laying, and in some species (e.g., great spotted cuckoos, Clamator glandarius), males may lure the hosts away from the nest, allowing the female the opportunity for egg laying (Davies, 2000, 2011). In response, hosts have evolved behavioral responses that reduce parasitism, such as mobbing behavior toward brood parasites, nesting in more concealed locations, and adopting defensive nest architectures (e.g., narrow entrance tubes; Davies, 2000, 2011). Also, parasite chicks evolved behaviors to increase the parental care provided by the hosts that range from ejecting host eggs/chicks from the nest in order to avoid competition of food provisioning, to increased begging abilities to claim an unfair share of food when competing with host chicks (Davies, 2000, 2011).

\section{3 | Heterospecific cooperation}

There are numerous cases in which individuals belonging to different species cooperate with each other. As it stands, such mutualisms provide the foundation for the world as we know it, starting from endosymbionts allowing the evolution of eukaryotic cells to the diversity of flowering plants depending on pollinators and root symbionts (Bronstein, 1994, 2015).

A particularly interesting example of interspecific cooperation that is explicit on communication and behavioral coordination is the cooperative hunting between groupers of the genus Plectropomus and various partner species (Bshary et al., 2006; Vail et al., 2013, 2014). The groupers use strong acceleration to try to capture prey, which in turn typically tries to escape into crevices that are inaccessible for the groupers. The groupers' partner species can access such hiding prey: Moray eels move through crevices, octopus insert their arms, and Napoleon wrasse may crush the reef structure. Groupers use two signals to elicit joint hunting. A rapid shaking of the head while in horizontal position serves to initiate a hunt with moray eels, while a headstand shake serves to attract partners to a crevice where prey is hiding (Bshary et al., 2006). The latter signal fulfills five key criteria for referential gestures (Vail et al., 2013). According to field observations in the Red Sea, following a grouper in hunting 
mode for 120 min yields a $70-80 \%$ chance of observing a signaling event, and a single collaborative hunting event with a moray eel can last up to $93 \mathrm{~min}$. The understanding of groupers when they need a partner, and their ability to choose between partners of different quality, rivals the abilities of chimpanzees in similar laboratory experiments (Melis et al., 2006; Vail et al., 2014).

As another example, the genus Labroides evolved from corallivorous ancestors into the most sophisticated cleaner fish on coral reefs (Cowman et al., 2009; Figure 1d). Their interactions with "client" fish have been used to demonstrate various key concepts developed to explain intraspecific cooperation. Cleaners prefer to eat client mucus rather than ectoparasites (Grutter \& Bshary, 2003), which creates conflicts. In order to obtain a good cleaning service, clients use punishment, partner switching, and assess the cleaners' interactions with other clients to then seek or avoid a cleaner (Bshary \& Grutter, 2005, 2006). In turn, cleaners are more cooperative if observed by bystanders (Pinto et al., 2011) and reconcile with clients that responded to a cheating act with aggression (Bshary \& Würth, 2001). Cleaners track their clients' behavior and act, for example, on clients' likelihood to swim off if not serviced immediately (Triki et al., 2019). Interactions with clients also affect conspecific interactions, with males punishing females for cheating joint clients, adjusting the severity of punishment to the stakes (Raihani et al., 2010, 2012). As cleaners obtain almost $100 \%$ of the food from about 2000 cleaning interactions per day (Côté, 2000; Grutter, 1995), their performance in these interspecific social interactions is obviously under strong selection.

\section{4 | Heterospecific social groupings}

Heterospecific social groups, such as mixed-species fish shoals, bird flocks, and mammalian herds, are common in nature across a range of aquatic and terrestrial ecosystems (Harrison \& Whitehouse, 2011; Lukoschek \& McCormick, 2000; Paijmans et al., 2019; Sridhar et al., 2013; Stensland et al., 2003). Adaptive explanations for heterospecific grouping have claimed the similar fitness benefits to those proposed for single-species groupings, including reduced predation risk, due to collective vigilance and/or predator confusion effect, enhanced foraging efficiency, and more efficient movement in the environment, due to increased aerodynamics or hydrodynamics (Goodale et al., 2020; Paijmans et al., 2019). These benefits have to out weight the costs associated with social grouping, namely increased competition for food and increased detection by predators. However, differences between species in any of these components will give rise to species-specific cost-benefit trade-offs in heterospecific grouping. For example, feeding competition is lower between species than within species, and niche overlap in resource exploitation will determine interspecific competition. Similarly, species with different sensory modalities and/or perceptual abilities will complement each other's efficiency in the detection of shared predators (e.g., Meise et al., 2019; Schmitt et al., 2014; Stears et al., 2020). In principle, these conditions favor the formation of mixed-species groups that optimize each other's grouping benefits (Terborgh, 1990). Recently, a model has been proposed which explains patterns of species associations in mixed-species groups based on net benefits to individuals resulting from the multiple trade-offs of differences between species, as well as from the trade-off arising from overall group size (Paijmans et al., 2019). Hence, although the literature on grouping behavior has mainly focused on single-species groups (for a review, see Ward \& Webster, 2016), the adaptive value of grouping behavior is better understood if heterospecific grouping is also considered.

\section{5 | Intraspecific predation}

Although predation is commonly seen as an interspecific interaction, intraspecific predation (aka cannibalism) is widespread in the animal kingdom, from invertebrates (e.g., arachnids, insects) to all vertebrate classes (Elgar \& Crespi, 1992; Fox, 1975; Polis, 1981). It has been shown to play a significant role in population dynamics and in the competitive relationships of organisms, since it can reduce population size and alter age structure in face of shortage of resources or high population density (e.g., Van Buskirk, 1989; Fincke, 1994; Lloyd, 1968; Park et al., 1965; Wagner \& Wise, 1996). Cannibalism, including filial cannibalism, is nutritionally beneficial, increasing survival, reducing developmental time and increasing fecundity, hence having an effect on the fitness of cannibals (FitzGerald, 1992; Fox, 1975; Manica, 2002; Matsumoto et al., 2018; Sonleitner \& Guthrie, 1991; Spence \& Carcamo, 1991; Tschinkel, 1993). Such fitness benefits may provide a selective advantage that leads to the evolvability of cannibalism (e.g., Eickwort, 1973; Stevens, 1989). Filial cannibalism, when organisms eat one's own offspring, is a sub-type of intraspecific predation that also has clear fitness implications. It is particularly common in fish where it has been regarded as an adaptive trade-off between present (i.e., offspring survival) and future (i.e., feeding in order to increase nutritional status) reproductive success (FitzGerald, 1992; Manica, 2002). However, some recent evidence suggests that, at least in some cases, filial cannibalism does not have nutritional benefits but is rather a way to end the parental phase and restart courtship, suggesting that this is infanticide rather than cannibalism (e.g., Matsumoto et al., 2018).

In conclusion, intraspecific predatory behavior may have fitness implications that are analogous to those of other intraspecific social processes such as dispersal, spacing behavior, or dominance hierarchies. Its effects can hence rival the effects of interspecific predation, blurring the distinction between social behavior and predator-prey interactions.

\section{3 | A MECHANISTIC PERSPECTIVE}

Conspecific and heterospecific interactions impose similar selective pressures on sensory and cognitive mechanisms that regulate social behavior. In order to be successful in both types of interactions, individuals need to be able to recognize relevant interactants 
and discriminate them into meaningful categories (e.g., potential mate, competitor, cooperator/mutualist, predator) and to use adaptive decision-making rules in order to adjust a flexible behavioral response accordingly. A key question is to what extent the functional categories of behavior observed in intraspecific interactions (i.e., aggression, mating, parenting) are homologous (i.e., share the same proximate mechanisms) to those observed in heterospecific interactions. In this respect, two scenarios are possible for the evolution of the proximate mechanisms (genes, neural circuits, cognitive processes) underlying a behavior used in both conspecific and heterospecific interactions: (1) They evolved first in a conspecific context and were later co-opted to be used in interspecific interactions, when species first evolved in allopatry and later became in contact, or (2) a shared mechanism evolved simultaneously toward both conspecifics and heterospecifics, when species evolved sympatrically.

\section{1 | Social recognition and discrimination}

In order to respond adequately to social interactions, animals have to discriminate interactants into functional categories. A major recognition category that has been considered in evolutionary behavioral ecology is species recognition, given its importance for the differential expression and response to mating behaviors among closely related species, hence playing a key role in restricting gene flow and consequently in behavioral isolation and speciation. Hence, animals produce a variety of species-specific stereotypic behaviors (signals) in different sensory modalities (e.g., acoustic, chemical, visual) to communicate with each other in the scope of intraspecific social interactions, and their sensory/perceptual mechanisms are tuned to respond to these signals (aka conspecific recognition; e.g., pheromones in insects and mammals, Coyne et al., 1994, Brennan $\&$ Kendrick, 2006; Lebreton et al., 2017; body coloration in fish, Seehausen \& van Alphen, 1998, Couldridge \& Alexander, 2002, Williams \& Mendelson, 2011; vocalizations in amphibians and birds, Gerhardt, 1994, Toledo et al., 2015, Louder et al., 2019). Therefore, animals are usually able to discriminate between conspecific and heterospecific social signals and these conspecific signals are categorically represented in the nervous system. Thus, one possibility for the occurrence of heterospecific interactions is that the same cognitive and sensory systems may be used in signal recognition toward heterospecifics of closely related species that phenotypically resemble conspecifics (Ord et al., 2011), as supported by a literature review that found heterospecific aggression to be more pronounced among congeneric heterospecific individuals, than toward more distantly related genera (Peiman \& Robinson, 2010).

Perceptual filters for conspecific signals have been well studied in acoustic communication in birds where conspecific vocalizations elicit differential behavioral responses that are paralleled by heightened neural activity in distinct nuclei of the avian auditory forebrain (Louder et al., 2019), often based on innate predispositions toward conspecific vocalizations (Araki et al., 2016; Hauber et al., 2013; Long et al., 2002; Whaling et al., 1997). Experience with heterospecific vocalizations during critical periods in development (e.g., zebra finch nestlings raised with Bengalese finch tutors) may lead to a learned preference and expression of heterospecific song, which is accompanied by a specialization of auditory cortex neurons for the tutor song, through tuning of spectrotemporal receptive fields of the neurons (Moore \& Woolley, 2019) and a differential transcriptional responses suggestive of release of inhibition toward the heterospecific stimulus (Louder et al., 2018). While such tutor experiments described above represent an artificial situation where developmental mechanisms have not been under selection, a natural situation where nestlings are raised by heterospecific tutors is offered by brood parasites. In the pin-tailed whydah (Vidua macroura), an obligatory brood parasite, adults still recognize and express a behavioral preference for their own host parent species vocalizations, paralleled by an increased neural response within the auditory forebrain homologous to the one observed in phylogenetic related non-parasitic species that are raised by their biological parents (Louder et al., 2016). Studies in another obligatory brood parasite, the brown-headed cowbird (Molothrus ater), suggest that this is apparently made possible through an inborn predisposition to a password-like conspecific chatter call, which not only identifies conspecifics but triggers social learning of other conspecific traits, including song (Hauber et al., 2001). It has recently been shown that the chatter call induces increased expression of the immediate early gene ZENK, used as a marker of neural activity, in the caudal medial nidopallium (NCM) in juveniles, whereas exposure to either conspecific or heterospecific songs elicits higher gene expression in a experience-dependent manner (Lynch et al., 2017). Thus, in parasitic cowbirds the NCM has been evolutionarily co-opted to selectively recognize a species-specific password chatter, allowing juvenile cowbirds raised by different host species to avoid imprinting on heterospecifics, while recently experienced song is still represented in the caudal medial mesopallium (CMM).

While species identity is of great biological relevance in a reproductive context, it is expected that selection may have acted irrespective of species boundaries to promote the recognition of relevant interactant categories in other ecological contexts, like competition for resources. Indeed, it has been shown in experimental settings that species that live in sympatry with heterospecific competitors display higher aggressive responses toward them than allopatric ones, suggesting that heterospecific competitor recognition was enhanced in sympatry (Grether et al., 2009). Furthermore, differential aggressive responses have been reported toward heterospecific members of the same competitor species that pose different levels of threat, suggesting an ability to discriminate heterospecifics into different threat categories. For example, neotropical cichlid fish that share breeding grounds with heterospecifics are more aggressive toward heterospecific nonbreeding individuals, that pose a threat to their offspring, than to heterospecific breeders, using body coloration as a recognition cue of heterospecific breeding status (Lehtonen et al., 2010, 2015). Interestingly, when exposed to manipulated territorial intrusions individuals of allopatric populations do not show 
an adjustment of their aggressive response in relation to heterospecific color markings that are associated with different levels of threat (Lehtonen et al., 2016), highlighting the importance of coevolution and learning in the categorization of heterospecific interactants. Interestingly, the same social signal can be differentially perceived by the different sexes of another species. In tungará frogs (Physalaemus pustulosus), the calls of the heterospecific (Physalaemus petersi) elicit a vocal response in males but fail to elicit a mating phonotaxis response in females (Bernal et al., 2007; Ryan \& Rand, 1995), and this sex difference in the behavioral response is mirrored by the neural response. Indeed, the activity of the midbrain auditory region, as measured by the expression of an immediate early gene (egr-1), is elevated in males in response to both conspecific and heterospecific calls, whereas in females, it is only elevated in response to conspecific calls (Hoke et al., 2008). Therefore, it seems that the perceptual system of males and females can be shaped by different selection pressures for the discrimination or not of relevant social categories: for males, both conspecific and heterospecific males represent competitors for mating territories, whereas for females, only the conspecific call is relevant for sexual selection.

\subsection{Social learning and memory}

The ability to successfully interact with other behavioral agents, either conspecific or heterospecific, relies to a large extent on flexible behavioral responses that require learning and memory (Taborsky and Oliveira, 2012). In the scope of social interactions, individuals can learn from observing others rather than by costly trial-and-error strategies (aka social learning; Dall et al., 2005; Danchin et al., 2004; Heyes, 1994). This form of learning is widespread in animals, from invertebrates to mammals (e.g., Brown \& Laland, 2003; Galef \& Giraldeau, 2001; Galef \& Laland, 2005; Leadbeater \& Chittka, 2007). Conspecifics have been traditionally seen as the primary source of information for social learning (Hoppitt \& Laland, 2013). However, heterospecifics can be as valuable as information sources as long as they share the same ecological needs (Avarguès-Weber et al., 2013). In fact, heterospecific social learning has been demonstrated for food location, habitat choice, and predator evasion across a wide range of species (Table 1 for selected examples). A peculiar case of social learning that blends intraspecific and heterospecific aspects involves juvenile cleaners learning from adults how to interact with various client types (Truskanov et al., 2020). From the many examples available in the literature, three patterns are worth noting. First, the diversity of examples shows that the occurrence of heterospecific social learning is taxonomically as widespread as conspecific social learning, ranging from invertebrates to mammals, hence not suggesting more complex cognitive demands. Moreover, social information transfer may occur across widely different taxa. For example, Augabries flat lizard (Platysaurus capensis), which feed on ripe figs, use birds, that also feed on figs, flocking in fig trees for food location (Whiting and Greeff, 1999), whereas yellow-casqued hornbills (Ceratogymna elata), which are vulnerable to predation by crowned eagles (Stephanoaetus coronatus) but are not preyed on by leopards (Panthera pardus), respond to sympatric Diana monkey eagle alarm calls but not to the leopard alarm call (Rainey et al., 2004). Secondly, individuals of other species can be as good demonstrators as conspecifics (e.g., bumblebees: Dawson \& Chittka, 2012; birds: May \& Reboreda, 2005; lizards: Damas-Moreira et al., 2018), and more efficient than non-social cues, suggesting that organisms may have a predisposition to social cues when learning about food sources (Dawson \& Chittka, 2012). Finally, the fact that phylogenetically closely related species show marked differences in the use of heterospecific information (e.g., Coolen et al., 2003; Magrath et al., 2009, Magrath and Bennett, 2012; Kitchen et al., 2010; Avarguès-Weber et al., 2013) suggests that heterospecific social learning only emerges if it is under selection (e.g., high predation risk).

From a proximate causal perspective, heterospecific social learning may rely on relatively simple forms of classical conditioning as in learning to associate alarm calls with a predator appearance (Avarguès-Weber et al., 2013), but also on second-order conditioning based on indirect associations (Dawson et al., 2013). This is a potential explanation for social learning about food location, where the indirect association between a location or cue (second-order conditioned stimulus) and the reward (food) is established by the prior association of foraging conspecifics/heterospecifics (first-order conditioned stimulus) with the food, as in the case of nine-spined sticklebacks (Pungitius pungitius) learning a food location after observing either conspecifics or three-spined sticklebacks (Gasterosteus aculeatus) eating in the same spatial position (Coolen et al., 2003).

Alternatively, perceptual resemblance of conspecific and heterospecific cues may trigger appropriate responses, as it has been shown for bird alarm calls and for bat distress calls (de Kort and Cate, 2001; Fallow et al., 2011; Russ et al., 2004), and perceptual resemblance should share the same neural mechanisms. In accordance with this prediction, it has been shown that playbacks of black-capped chickadee mobbing calls, which are used to recruit conspecifics and other avian species to mob perched predators (Ficken \& Witkin, 1977), elicited similar patterns of forebrain secondary auditory cortex activation (i.e., CMM and NCM) as measured by ZENK expression, in both conspecific and heterospecific (i.e., mountain chickadee, Poecile gambeli) listeners. Interestingly, black-capped chickadees produce referential mobbing calls that convey the degree of threat posed by different predators (Templeton et al., 2005), and referential mobbing calls signaling a low-threat predator elicited lower activations of the auditory cortex in both chickadee species (Avey et al., 2011). Therefore, the level of activation of the secondary auditory cortex seems to reflect the level of assessed threat irrespective of source of information, hence suggesting a shared neural substrate to encode the socially transmitted information about predation risk. Spatial cognition is another key element for successful social interactions. Within the brain, spatial cognition has been related 


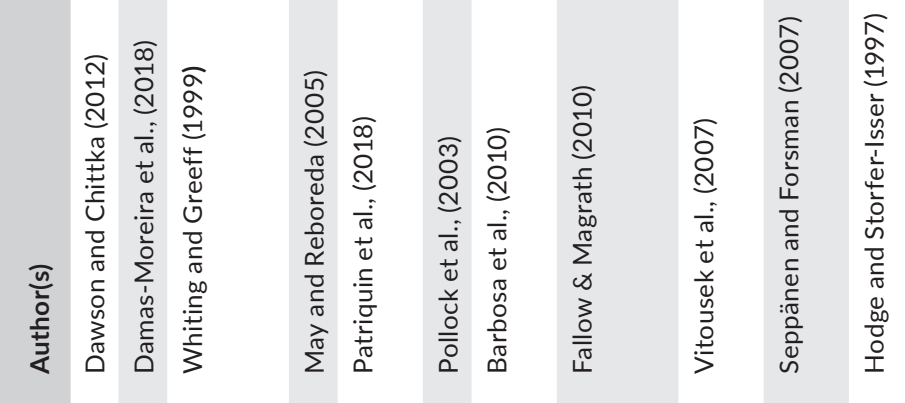

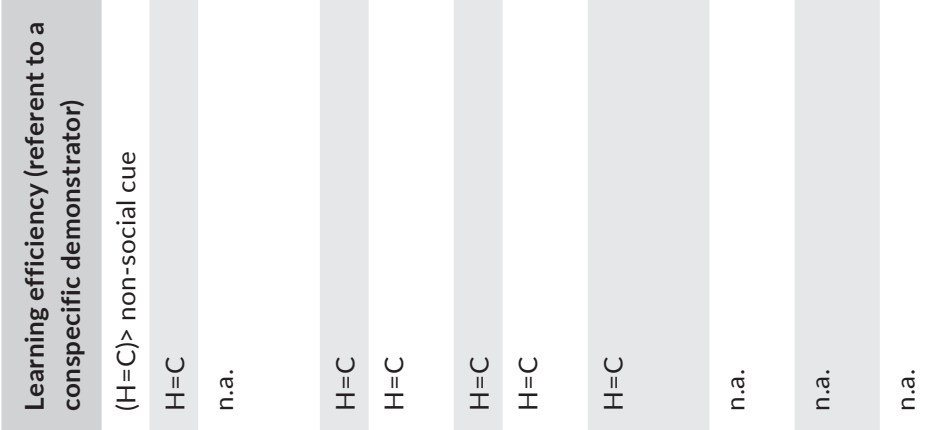

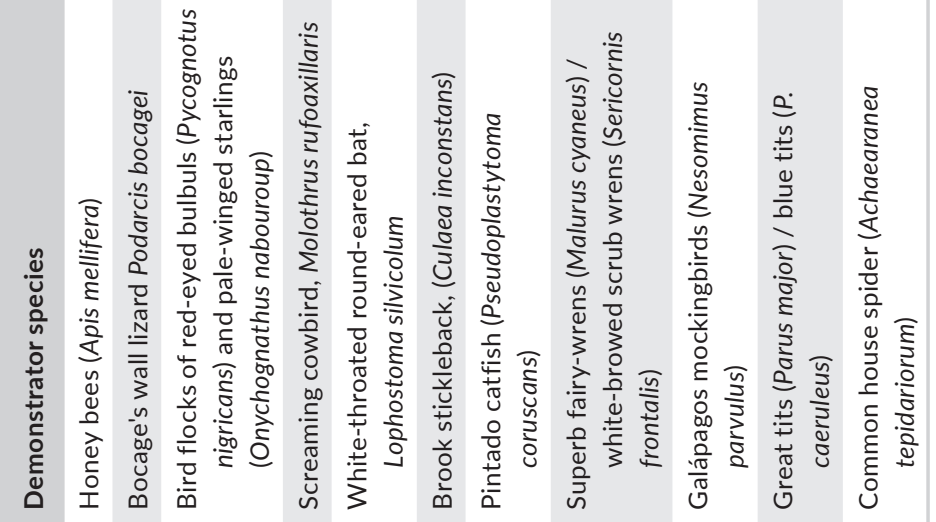

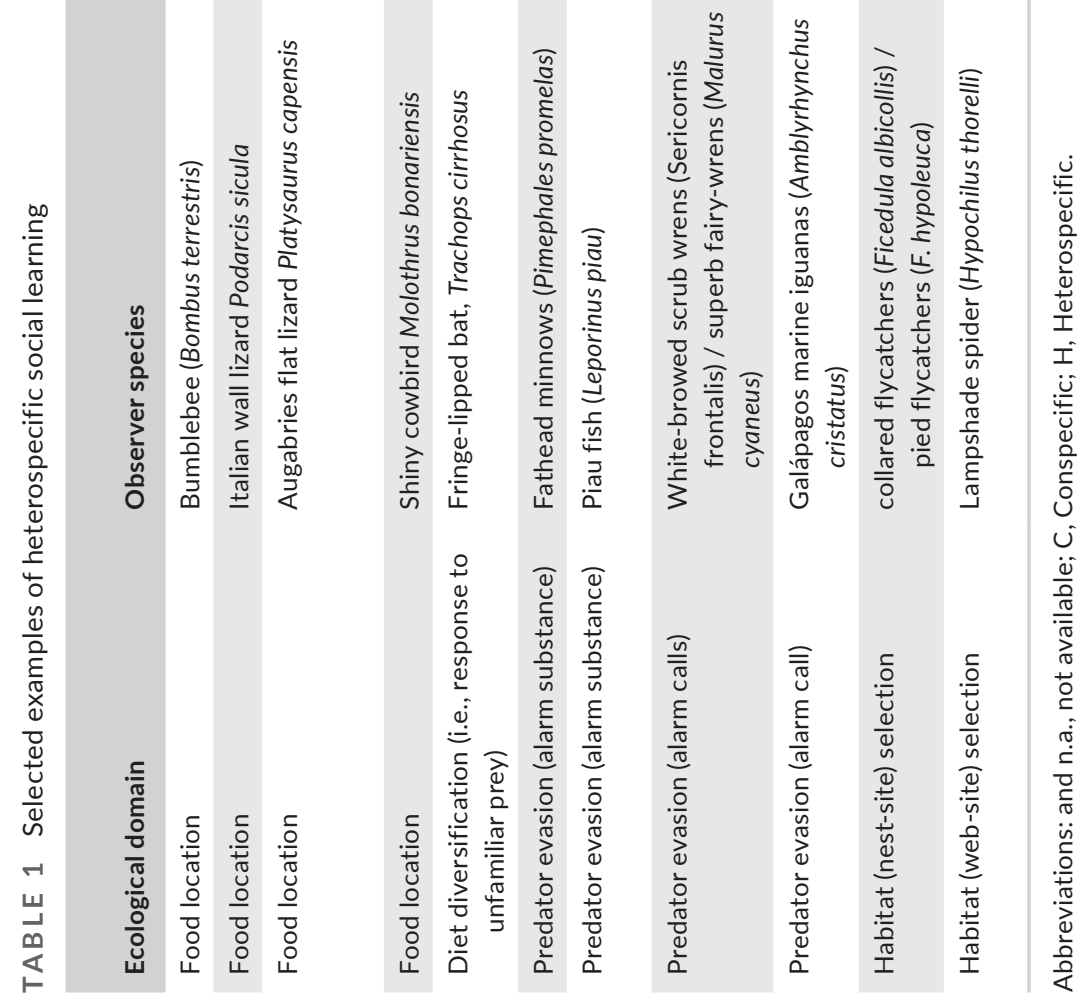


to the hippocampus in mammals and to homologous structures (i.e., medial pallium) in other vertebrates (Hartley et al., 2013). In rodents, the hippocampal complex (i.e., hippocampus and entorhinal cortex) contains a population of neurons (aka place cells) that respond to specific locations in the environment and another cell population (aka grid cells) which fires when an animal enters an environment with geometrically patterned locations hence providing a spatial cognitive map of the environment (Hafting et al., 2005; Hartley et al., 2013; O'Keefe, 1979). This map is also capable of processing other spatially representable information, hence providing a spatially based system (aka memory map) for encoding declarative memories (Eichenbaum, 2017; Jeffery, 2018), which is relevant for social memory. Direct evidence of the involvement of the hippocampus in mapping the social landscape has been recently demonstrated in bats, where specific place cells map the presence of other bats in the environment (Omer et al., 2018). Also in rats, the cornu ammonis 2 (CA2) area of the hippocampus has been shown to use place fields to encode information about conspecifics (Alexander et al., 2016). Thus, the hippocampus may play a more relevant role in social cognition than originally thought.

In wild animals, hippocampus size has been shown to be evolutionarily shaped by conspecific interactions, namely the spatial range of mating interactions and social group size that may cause interspecific and/or intraspecific intersexual variation (e.g., primates: Todorov et al.,I., 2019; voles (Rodentia: Microtus): Boonstra et al.,l., 1993; Jacobs et al., 1990; desert kangaroo rats (Dipodomys spp.): Jacobs and Spencer, 1994; Langley, 1994; deer mice (Peromyscus maniculatus): Galea et al., 1996; giant panda (Ailuropoda melanoleuca) and Asian small-clawed otter (Aonyx cinereus): Perdue et al., 2011; intertidal blenniid fish species [i.e., shanny (Lipophrys pholis) and Azorean rock-pool blenny (Parablennius parvicornis)] (Costa et al., 2011)). Once again, parasitic brood parasites offer a great system to test for interspecific hippocampus size adjustments, since they need to search for and monitor potential host nests in which to lay their eggs, hence facing a selection pressure for heightened spatial cognition. Moreover, there is interspecific variation among brood parasites in the role of males in host nest search behavior, and there are nonparasitic closely related species that can be used as a phylogenetic reference of the ancestral state. As predicted, hippocampi size is larger in brood parasitic species when compared to closely related non-parasitic species (Reboreda et al., 1996; Sherry et al., 1993), and there is a sex difference with females having larger hippocampi in species where females are not assisted by the males in searching for host nests [i.e., brown-headed cowbird (Molothrus ater) and shiny cowbird (M. bonariensis)], but not in species where both sexes search for nest [i.e., screaming cowbird (M. rufoaxillaris); Sherry et al., 1993; Reboreda et al., 1996]. Moreover, the sex differences present during the breeding season in the shiny cowbird disappear during the nonbreeding season, when there are also no sex differences in spatial behavior (Clayton et al., 1997). The sex difference in hippocampi size in brown-headed cowbirds is explained by enhanced adult hippocampal neurogenesis in females, which increases in the post-breeding season, suggesting that old memories for host nest sites may be lost through hippocampal reorganization following breeding (Guigueno et al., 2016). In summary, heterospecific interactions seem to also impose a selection regime that leads to cognitive and neurobiological specializations, as observed for conspecific interactions.

\subsection{Social decision-making}

Social decision-making requires the integration of multimodal sensory information about social stimuli with information stored in memory regarding previous social experience in order to produce an adaptive behavioral response to the perceived social environment.

An evolutionarily conserved brain social decision-making network (SDMN) has been proposed to regulate the expression of social behavior across vertebrates (O'Connell \& Hofmann, 2011, 2012). This network integrates two previously described networks: the social behavior network and the mesolimbic reward circuit (Adinoff, 2004; Goodson, 2005; Newman, 1999), with the former regulating the expression of the social repertoire of the species and the latter providing a mechanism for the reinforcement of adaptive behavioral responses. Subsequently, there have been proposals to expand this network to include also brain regions related to the sensory integration and salience assessment of social information (e.g., insular cortex for sensory integration and anterior olfactory nucleus and prefrontal cortex for social salience assessment in rodents; Johnson et al., 2017; Rogers-Carter \& Christianson, 2019). Irrespective of the specific structure of this network, two key features of this conceptual proposal are that (1) social information is processed in a network of reciprocally interconnected brain nodes emphasizing distributed, interregional information processing, such that the expression of social behavior (i.e., aggression, mating, parenting, cooperation) is better reflected by the overall profile of activation across the different loci in the network rather than by the activity of a single node (Johnson et al., 2017; Teles et al., 2015); (2) different combinations of activation across nodes and variation in the strength of the connections among them have the potential to generate unlimited variation in social behavior (Cardoso et al., 2015; Goodson \& Kabelik, 2009); and (3) the nodes of the SDMN extensively express receptors for steroids and neuropeptides (O'Connell \& Hofmann, 2011, 2012), thus allowing the modulation of the activity of this network by hormones and neuromodulators that promote the integration of organismal state in social decision-making (e.g., adjust expression of mating behavior to gonadal maturation state).

From a mechanistic perspective, our proposal of extending the concept of social behavior to heterospecific interactions is that the SDMN must have been evolutionarily co-opted to regulate also social decision-making toward heterospecific interactants. Therefore, one can generate two predictions: (1) Similar patterns of activation of the SDMN should be observed in response to social interactions with conspecifics vs. heterospecifics in the same functional domain (e.g., response to conspecific vs. heterospecific territorial intrusion) 
(a)

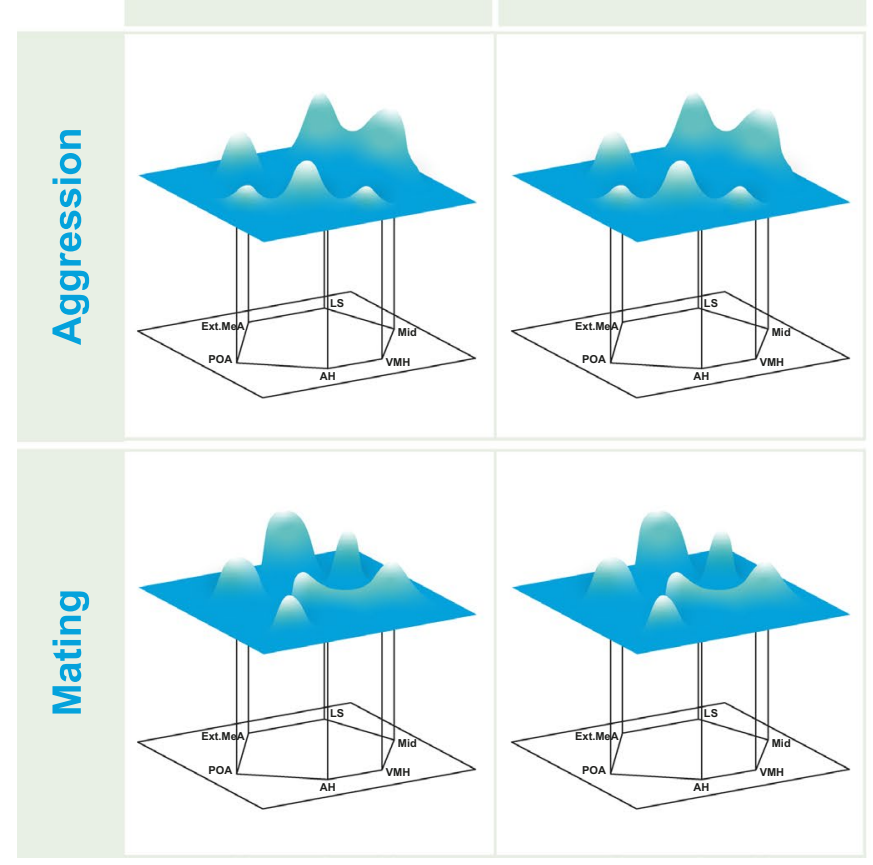

(b)

$$
\text { Conspecific Heterospecific }
$$

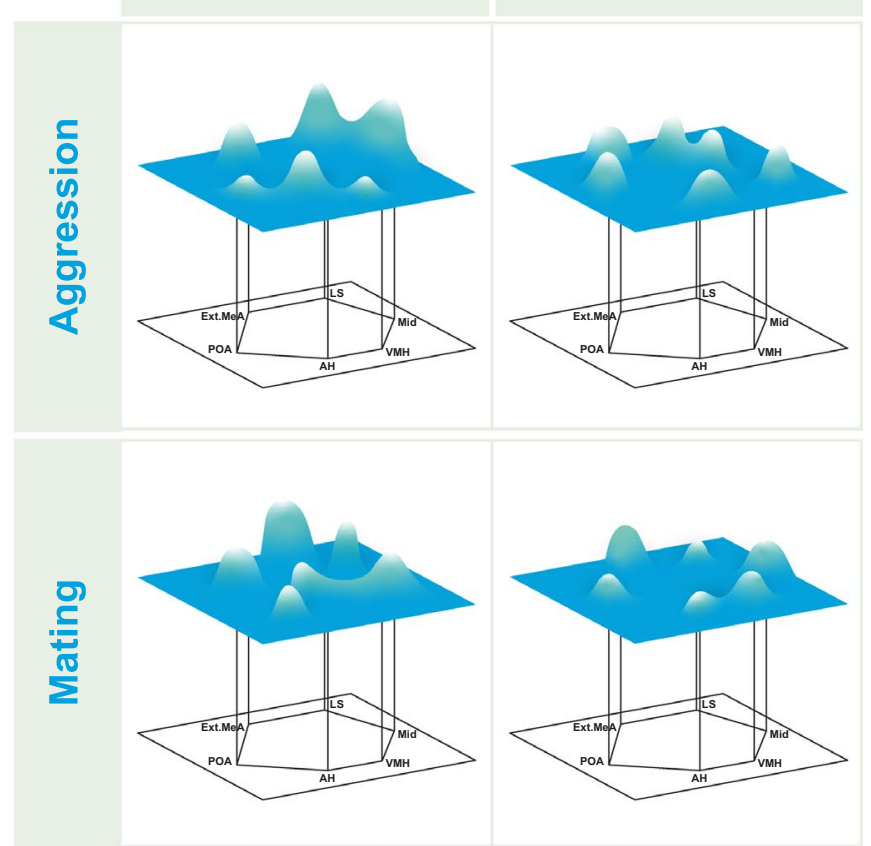

FIGURE 2 The social decision-making network (SDMN) is an evolutionary conserved brain circuit that regulates the expression of a variety of social behaviors (i.e., aggression, mating, parenting, cooperation) across vertebrates, by differential activation across the different loci in the network rather than by the activity of a single node. (a) Scenario of the evolution of a shared SDMN pattern for both conspecific and interspecific interactions, such that the same type of interaction is paralleled by the same pattern of activation irrespective of the interaction being directed toward a conspecific or a heterospecific. (b) Scenario of the evolution of separate SDMN patterns for conspecific and heterospecific interactions, such that within each type of interaction different patterns of SDMN activation are observed depending on the species of the interactant

(Figure 2), and (2) the same neuromodulators/hormones should have similar effects on social behaviors in the same functional domain directed toward conspecifics vs. heterospecifics.

To the best of our knowledge, the first prediction has never been directly tested by contrasting the patterns of activity across the SDMN in conspecific vs. heterospecific interactions in the same functional domain. However, indirect evidence can be gathered by comparing the relative development of the forebrain, that harbors most of the nodes of the SDMN, between relevant social conditions. In a recent study with cleaner wrasse, which engages in complex social interactions with heterospecific client reef fish species, the relative forebrain size correlated positively with the complexity of their intra-and interspecific social environment, for high-performing, but not for low-performing individuals, in an ecologically relevant cognitive task for heterospecific interactions (Triki et al., 2020). This suggests that cleaners with relatively larger forebrains used optimal social decision-rules for the level of social complexity they experience and that heterospecific interactions are shaping the forebrain, and putatively its SDMN, development.

Regarding the second prediction, some studies on nonapeptides are available that support it. The involvement of oxytocin, whose receptors are extensively expressed in the SDMN and that is known to regulate social affiliation across a wide range of species (Donaldson \& Young, 2009; Jurek \& Neumann, 2018;
Knobloch \& Grinevich, 2014), in social bonding toward conspecifics and heterospecifics has been tested in dogs (Canis familiaris). When sprayed with oxytocin, dogs displayed more affiliative behaviors both toward their owners and toward other dogs (Romero et al., 2014), suggesting a shared causal role of this neuropeptide on conspecific and heterospecific social bonding. Moreover, exogenous administration of oxytocin to dogs also increases gazing toward owners, which elicit increased oxytocin levels in owners, consequently facilitating owners' affiliation toward, which in turn lead to further increases in oxytocin concentration in dogs (Nagasawa et al., 2015). Arginine-vasopressin/vasotocin (AVP/ AVT) is another key neurohormone regulating the modulation of several intraspecific social behaviors, such as social approach/ withdrawal and aggression (Goodson \& Bass, 2001; Goodson \& Thompson, 2010). Research on cleaner fish (L. dimidiatus) reveals how the expression of AVT has been co-opted for interactions with heterospecific client fish. Cleaners evolved smaller and less numerous AVT-ir neurons in the gigantocellular preoptic area (gPOA) compared to non-cleaners, apparently to reduce AVT production to be able to approach the diversity of typically larger client species (Mendonça et al., 2013). Indeed, administration of AVT causes cleaners to reduce cleaning interactions (Soares et al., 2012) and to be less willing to feed against preference (Cardoso, Teles, et al., 2015), indicating that AVT makes them perceive 
cleaning interactions as more competitive situations. Together, these results suggest that oxytocin regulation of affiliative behavior in dogs and AVT regulation of social interactions in cleaner fish have been co-opted for heterospecific interactions, which may have led to the coevolution of human-dog bonds and cleaning mutualistic behavior, respectively.

\subsection{Physiological responses to social interactions}

Peripheral hormones and physiology both respond to and regulate conspecific social interactions as a way to promote brain-body integration in the scope of social behavior.

Two hormone families have been consistently shown to promote such phenotypic integration: androgens, in the scope of agonistic and reproductive interactions, and glucocorticoids, in the scope of the physiological challenge imposed by social interactions in general (Archer, 2006; Oliveira, 2009; Wingfield et al., 1990). Similarly, although less studied, heterospecific interactions may also elicit shared physiological responses. Indeed, in the territorial algae farmer fish (dusky gregories, Stegastes nigricans) territorial intrusions either by conspecific or by heterospecific intruders elicited similar levels of aggressive response and an increase in cortisol levels that was positively related with the levels of aggression, irrespective of the intruders' species (Ros et al., 2014). Regarding the cellular stress response, upregulation of heat-shock protein genes (HSP70) has been shown to respond to interspecific interactions in some species (e.g., aggregating anemone, Anthopleura elegantissima; Rossi \& Snyder, 2001) but not in others (e.g., porcelain crabs, Petrolisthes spp.; Gunderson et al., 2017), with the reasons for these interspecific differences not being clear. In contrast, interaction or the mere exposure to predators has a consistent effect on the cellular response in prey (Gunderson et al., 2017). Finally, red-winged blackbirds (Agelaius phoeniceus), which respond aggressively toward other conspecific blackbird males that compete for breeding territories, and toward females of the brood parasite brown-headed cowbird, also show partially similar transcriptional responses. Both heterospecific and conspecific aggressive responses triggered a downregulation of immune response genes, but only the latter elicited an increase in singing behavior, which was associated with an upregulation of genes associated with metabolic processes (Louder et al.,I., 2020). Thus, conspecific aggression and heterospecific aggression share similar physiological responses for the similar component of the interaction (i.e., physiological stress).

Testosterone influences the expression of aggressive behavior in males of many vertebrates, especially in the context of territoriality (Wingfield, 1994; Oliveira, 2004). Conversely, aggressive interactions induce an increase in circulating androgen levels, which has been interpreted as a way to promote a brain-body integrated flexible response to social challenges (Oliveira, 2009; Goymann et al., 2019). Interestingly, the source of androgens regulating aggressive behavior differs seasonally with gonadal androgens being the main source during the breeding season and androgens produced locally in the brain being the main effectors outside the breeding season (Soma, 2006). This suggests that mating and non-mating competitive interactions may be regulated by different androgen-based mechanisms, with the former promoting a brain-gonad integration that is not relevant in the latter. Hence, it is expected that although androgens should promote aggressive behavior in both mating and non-mating interactions, only the former should elicit a response in circulating androgens, which originate predominantly in the gonads. The available data on androgens and interspecific interactions fully support these predictions. In fish (S. nigricans) defending feeding territories, a blocker of androgen receptors (flutamide) suppresses aggressive behavior toward both intraspecific and heterospecific intruders, and neither type of intruder elicits a response in circulating androgens (Vullioud et al., 2013). Similarly, Eastern Bluebirds (Sialia sialis) respond to simulated intrusions of both conspecifics and heterospecifics (house Sparrows, Passer domesticus), and a positive correlation as found between testosterone baseline levels and the aggressiveness displayed toward heterospecific intruders (Arboleda \& Khan, 2016). Finally, in sympatric competing warblers the species (Townsend's warblers, Dendroica townsendi) that is aggressively dominant and outcompetes the other (hermit warblers, D. occidentalis) also exhibits higher androgen levels, and hybrids have intermediate androgen levels, suggesting that these hormonal differences are partially genetically based and regulate heterospecific competition (Owen-Ashley \& Butler, 2004).

\section{4 | CONCLUSION}

The aim of our paper was to highlight studies that show the similarities between intra- and interspecific interactions on both functional and mechanistic levels. Undoubtedly, more examples exist. Furthermore, we have not tried to compile studies that fail to show similarities. We are aware that the opening of the definition of social interactions to heterospecific agents creates the need to exclude other types of heterospecific interactions that happen at very different spatial or temporal scales, such as host-parasite interactions between multicellular organisms and their unicellular microbiome. Indeed, there are numerous described cases where there is an evolutionary arms race in which parasites have evolved mechanisms to modulate the expression of their host behavior (Hughes \& Libersat, 2019; Libersat et al., 2018) and hosts have evolved behavioral measures to counteract these effects (aka antiparasite behavior, Bush \& Clayton, 2018; Gray et al., 2012). In these cases, however, we argue that we should limit the scope of social behavior analysis to processes in which the behavior of both interactants occurs within similar temporal and spatial scales.

In the end, our aim as scientists should always be to understand animals from their perspective. As the species concept is a (generally very useful) human construct, we need to go beyond its simplicity and appreciate the variety of interspecific social interactions in order to understand how animals govern their social life. 


\section{ACKNOWLEDGEMENTS}

The authors would like to dedicate this paper to Michael Taborsky on the occasion of his academic retirement. During the writing of this review, RFO was funded by Fundação para a Ciência e a Tecnologia (FCT, grants: UIDB/04555/2020 and PTDC/BIA-COM/30627/2017) and RB by the Swiss National Science Foundation (Grant Number: 310030B_173334/1).

\section{ORCID}

Redouan Bshary (D) https://orcid.org/0000-0001-7198-8472

\section{REFERENCES}

Adinoff, B. (2004). Neurobiologic processes in drug reward and addiction. Harvard Reviews of Psychiatry, 12, 305-320.

Alexander, G. M., Farris, S., Pirone, J. R., Zheng, C., Colgin, L. L., \& Dudek, S. M. (2016). Social and novel contexts modify hippocampal CA2 representations of space. Nature Communications, 7 , 10300.

Araki, M., Bandi, M. M., \& Yazaki-Sugiyama, Y. (2016). Mind the gap: neural coding of species identity in birdsong prosody. Science, 354 , 1282-1287.

Arboleda, C. V., \& Khan, M. Z. (2016). Testosterone and heterospecific aggression in the adult eastern bluebird (Sialia sialis) during the nestling period. International Journal of Avian \& Wildlife Biology, 1, 5-11.

Archer, J. (2006). Testosterone and human aggression: an evaluation of the challenge hypothesis. Neuroscience \& Biobehavioral Reviews, 30, 319-345.

Avey, M. T., Hoeschele, M., Moscicki, M. K., Bloomfield, L. L., \& Sturdy, C. B. (2011). Neural correlates of threat perception: neural equivalence of conspecific and heterospecific mobbing calls is learned. PLoS One, 6, e23844.

Avarguès-Weber, A., Dawson, E. H., \& Chittka, L. (2013). Mechanisms of social learning across species boundaries. Journal of Zoology, 290(1), 1-11.

Bakker, T. C., Frommen, J. G., \& Thünken, T. (2017). Adaptive parasitic manipulation as exemplified by acanthocephalans. Ethology, 123, 779-784.

Barbosa, A. Jr, Magalhães, E. J., Hoffmann, A., \& Ide, L. M. (2010). Conspecific and heterospecific alarm substance induces behavioral responses in piau fish Leporinus piau. Acta Ethologica, 13, 119-126.

Barlow, G. W. (2000). Cichlid fishes: nature's grand experiment in evolution. Perseus.

Begon, M., Townsend, C. R., \& Harper, J. L. (1990). Ecology: from individuals to ecosystems, 4 th ed. Wiley-Blackwell.

Bergstrom, C., Bronstein, J. L., Bshary, R., Connor, R., Daly, M., Frank, S., Gintis, H., Keller, L., Leimar, O., Noë, R., \& Queller, D. (2003). Interspecific mutualism: puzzles and predictions. In P. Hammerstein (Ed.), Genetic and Cultural Evolution of Cooperation (pp. 241-256). MIT Press.

Bernal, X. E., Rand, A. S., \& Ryan, M. J. (2007). Sexual differences in receiver permissiveness to advertisement calls in túngara frogs, Physalaemus pustulosus. Animal Behaviour, 73, 955-964.

Boonstra, R., Xia, X., \& Pavone, L. (1993). Mating system of the meadow vole, Microtus pennsylvanicus. Behavioral Ecology, 4, 83-89.

Brennan, P. A., \& Kendrick, K. M. (2006). Mammalian social odours: attraction and individual recognition. Philosophical Transactions of the Royal Society of London B, 361, 2061-2078.

Bronstein, J. L. (1994). Conditional outcomes in mutualistic interactions. Trends in Ecology and Evolution, 9, 214-217.

Bronstein, J. L. (2015). Mutualism. Oxford University Press.
Brown, C., \& Laland, K. N. (2003). Social learning in fishes: a review. Fish and Fisheries, 4, 280-288.

Bshary, R., \& Würth, M. (2001). Cleaner fish Labroides dimidiatus manipulate client reef fish by providing tactile stimulation. Proceedings of the Royal Society of London B Biological, 268, 1495-1501.

Bshary, R., \& Grutter, A. S. (2005). Punishment and partner switching cause cooperative behaviour in a cleaning mutualism. Biology Letters, 1, 396-399.

Bshary, R., \& Grutter, A. S. (2006). Image scoring and cooperation in a cleaner fish mutualism. Nature, 441, 975-978.

Bshary, R., Hohner, A., Ait-el-Djoudi, K., \& Fricke, H. (2006). Interspecific communicative and coordinated hunting between groupers and giant moray eels in the Red Sea. PLoS Biology, 4, e431.

Bush, S. E., \& Clayton, D. H. (2018). Anti-parasite behaviour of birds. Philosophical Transactions of the Royal Society of London B, 373, 20170196.

Cardoso, S. C., Paitio, J. R., Oliveira, R. F., Bshary, R., \& Soares, M. C. (2015). Arginine vasotocin reduces levels of cooperative behaviour in a cleaner fish. Physiology \& Behavior, 139, 314-320.

Cardoso, S. D., Teles, M. C., \& Oliveira, R. F. (2015). Neurogenomic mechanisms of social plasticity. Journal of Experimental Biology, 218, 140-149.

Clayton, N. S., Reboreda, J. C., \& Kacelnik, A. (1997). Seasonal changes of hippocampus volume in parasitic cowbirds. Behavioural Processes, 41, 237-243.

Coolen, I., Bergen, Y. V., Day, R. L., \& Laland, K. N. (2003). Species difference in adaptive use of public information in sticklebacks. Proceedings of the Royal Society of London B, 270, 2413-2419.

Costa, S. S., Andrade, R., Carneiro, L. A., Gonçalves, E. J., Kotrschal, K., \& Oliveira, R. F. (2011). Sex differences in the dorsolateral telencephalon correlate with home range size in blenniid fish. Brain, Behavior and Evolution, 77, 55-64.

Côté, I. M. (2000). Evolution and ecology of cleaning symbioses in the sea. Oceanography and Marine Biology Annual Review, 38, 311-355.

Cowman, P. F., Bellwood, D. R., \& van Herwerden, L. (2009). Dating the evolutionary origins of wrasse lineages (Labridae) and the rise of trophic novelty on coral reefs. Molecular Phylogenetics and Evolution, 52, 621-631.

Couldridge, V. C. K., \& Alexander, C. J. (2002). Color patterns and species recognition in four closely related species of Lake Malawi cichlid. Behavioral Ecology, 13, 59-64.

Coyne, J. A., Crittenden, A. P., \& Mah, K. (1994). Genetics of a pheromonal difference contributing to reproductive isolation in Drosophila. Science, 265, 1461-1464.

Dall, S. R. X., Giraldeau, L.-A., Olsson, O., McNamara, J. M., \& Stephens, D. W. (2005). Information and its use by animals in evolutionary ecology. Trends in Ecology and Evolution, 20, 187-193.

Damas-Moreira, I., Oliveira, D., Santos, J. L., Riley, J. L., Harris, D. J., \& Whiting, M. J. (2018). Learning from others: an invasive lizard uses social information from both conspecifics and heterospecifics. Biology Letters, 14, 20180532.

Danchin, É., Giraldeau, L.-A., Valone, T. J., \& Wagner, R. H. (2004). Public information: from nosy neighbors to cultural evolution. Science, 305, 487-491.

Davies, N. B. (2000). Cuckoos, cowbirds and other cheats. Poyser.

Davies, N. B. (2011). Cuckoo adaptations: trickery and tuning. Journal of Zoology, 284, 1-14.

Dawson, E. H., \& Chittka, L. (2012). Conspecific and heterospecific information use in bumblebees. PLoS One, 7, e31444.

Dawson, E. H., Avargues-Weber, A., Chittka, L., \& Leadbeater, E. (2013). Learning by observation emerges from simple associations in an insect model. Current Biology, 23, 1-4.

de Kort, S. R., \& ten Cate, C. (2001). Response to interspecific vocalizations is affected by degree of phylogenetic relatedness in Streptopelia doves. Animal Behaviour, 61, 239-247. 
Donaldson, Z. R., \& Young, L. J. (2009). Oxytocin, vasopressin, and the neurogenetics of sociality. Science, 322, 900-904.

Eickwort, K. R. (1973). Cannibalism and kin selection in Labidomera clivicollis (Coleoptera: Chrysomelidae). American Naturalist, 107, 452-453.

Eichenbaum, H. (2017). The role of the hippocampus in navigation is memory. Journal of Neurophysiology, 117, 1785-1796.

Elgar, M. A., \& Crespi, B. J. (1992). Cannibalism: ecology and evolution among diverse taxa Oxford. Oxford University Press.

Fallow, P. M., Gardner, J. L., \& Magrath, R. D. (2011). Sound familiar? Acoustic similarity provokes responses to unfamiliar heterospecific alarm calls. Behavioral Ecology, 22, 401-410.

Fallow, P. M., \& Magrath, R. D. (2010). Eavesdropping on other species: mutual interspecific understanding of urgency information in avian alarm calls. Animal Behaviour, 79, 411-417.

Ficken, M. S., \& Witkin, S. R. (1977). Responses of black-capped chickadee flocks to predators. The Auk, 94, 156-157.

FitzGerald, G. J. (1992). Filial cannibalism in fishes: Why do parents eat their offspring? Trends in Ecology \& Evolution, 7, 7-10.

Fincke, O. M. (1994). Population regulation of a tropical damselfly in the larval stage by food limitation, cannibalism, intraguild predation and habitat drying. Oecologia, 100, 118-127.

Fox, L. R. (1975). Cannibalism in natural populations. Annual Reviews in Ecology and Systematics, 6, 87-106.

Galea, L. A., Kavaliers, M., \& Ossenkopp, K. P. (1996). Sexually dimorphic spatial learning in meadow voles Microtus pennsylvanicus and deer mice Peromyscus maniculatus. Journal of Experimental Biology, 199, 195-200.

Galef, B. G., \& Giraldeau, L.-A. (2001). Social influences on foraging in vertebrates: causal mechanisms and adaptive functions. Animal Behaviour, 61, 3-15.

Galef, B. G., \& Laland, K. N. (2005). Social learning in animals: empirical studies and theoretical models. BioScience, 55, 489-499.

Gerhardt, H. (1994). The evolution of vocalization in frogs and toads. Annual Review of Ecology and Systematics, 25, 293-324.

Goodale, E., Sridhar, H., Sieving, K. E., Bangal, P., Colorado, G. J., Farine, D. R., Heymann, E. W., Jones, H. H., Krams, I., Martínez, A. E., Montaño-Centellas, F., Muñoz, J., Srinivasan, U., Theo, A., \& Shanker, K. (2020). Mixed company: a framework for understanding the composition and organization of mixed-species animal groups. Biological Reviews, 95, 889-910.

Goodson, J. L. (2005). The vertebrate social behavior network: evolutionary themes and variations. Hormones and Behavior, 48, 11-22.

Goodson, J. L., \& Bass, A. H. (2001). Social behavior functions and related anatomical characteristics of vasotocin/ vasopressin systems in vertebrates. Brain Research Reviews, 35, 246-265.

Goodson, J. L., \& Thompson, R. R. (2010). Nonapeptide mechanisms of social cognition, behavior and species-specific social systems. Current Opinion in Neurobiology, 20, 784-794.

Goodson, J. L., \& Kabelik, D. (2009). Dynamic limbic networks and social diversity in vertebrates: from neural context to neuromodulatory patterning. Frontiers in Neuroendocrinology, 30, 429-441.

Goymann, W., Moore, I. T., \& Oliveira, R. F. (2019). Challenge Hypothesis 2.0: A fresh look at an established idea. BioScience, 69, 432-442.

Gray, B., Jacobs, A. C., Mora, A. B., \& Zuk, M. (2012). Antiparasite behavior. Current Biology, 22, R255-R257.

Grether, G. F., Losin, N., Anderson, C. N., \& Okamoto, K. (2009). The role of interspecific interference competition in character displacement and the evolution of competitor recognition. Biological Reviews, 84 , 617-635.

Grether, G. F., Anderson, C. N., Drury, J. P., Kirschel, A. N. G., Losin, N., Okamoto, K., \& Peimanet, K. S. (2013). The evolutionary consequences of interspecific aggression. Annals of the New York Academy of Sciences, 1289, 48-68.

Groning, J., \& Hochkirch, A. (2008). Reproductive interference between animal species. The Quaterly Review of Biology, 85, 257-282.
Grutter, A. S. (1995). Relationship between cleaning rates and ectoparasite loads in coral reef fishes. Marine Ecology Progress Series, 118, 51-58.

Grutter, A. S., \& Bshary, R. (2003). Cleaner wrasse prefer client mucus: support for partner control mechanisms in cleaning interactions. Proceedings of the Royal Society of London. Series B: Biological Sciences, 270, S242-S244.

Guigueno, M. F., MacDougall-Shackleton, S. A., \& Sherry, D. F. (2016). Sex and seasonal differences in hippocampal volume and neurogenesis in brood-parasitic brown-headed cowbirds (Molothrus ater). Developmental Neurobiology, 76, 1275-1290.

Gunderson, A. R., King, E. E., Boyer, K., Tsukimura, B., \& Stillman, J. H. (2017). Species as stressors: heterospecific interactions and the cellular stress response under global change. Integrative and Comparative Biology, 57, 90-102.

Hafting, T., Fyhn, M., Molden, S., Moser, M. B., \& Moser, E. I. (2005). Microstructure of a spatial map in the entorhinal cortex. Nature, 436, 801-806.

Hamilton, W. D. (1964). The genetical evolution of social behavior, I. Journal of Theoretical Biology, 7, 1-16.

Harrison, N. M., \& Whitehouse, M. J. (2011). Mixed-species flocks: An example of niche construction? Animal Behaviour, 81, 675-682.

Hartley, T., Lever, C., Burgess, N., \& O'Keefe, J. (2013). Space in the brain: How the hippocampal formation supports spatial cognition. Philosophical Transactions of the Royal Society B, 369, 20120510.

Hauber, M. E., Russo, S. A., \& Sherman, P. W. (2001). A password for species recognition in a brood-parasitic bird. Proceedings of the Royal Society B, 268, 1041-1048.

Hauber, M. E., Woolley, S. M. N., Cassey, P., \& Theunissen, F. E. (2013). Experience dependence of neural responses to different classes of male songs in the primary auditory forebrain of female songbirds. Behavioural Brain Research, 243, 184-190.

Heyes, C. M. (1994). Social learning in animals: categories and mechanisms. Biological Reviews, 69, 207-231.

Hodge, M. A., \& Storfer-Isser, A. (1997). Conspecific and heterospecific attraction: a mechanism of web-site selection leading to aggregation formation by web-building spiders. Ethology, 103, 815-826.

Hoke, K. L., Ryan, M. J., \& Wilczynski, W. (2008). Candidate neural locus for sex differences in reproductive decisions. Biology Letters, 4, 518-521.

Hoppitt, W., \& Laland, K. N. (2013). Social learning: an introduction to mechanisms, methods, and models. Princeton University Press.

Hughes, D. P., \& Libersat, F. (2019). Parasite manipulation of host behavior. Current Biology, 29, R45-R47.

Jacobs, L. F., Gaulin, S. J., Sherry, D. F., \& Hoffman, G. E. (1990). Evolution of spatial cognition: Sex-specific patterns of spatial behavior predict hippocampal size. Proceedings of the National Academy of Sciences USA, 87, 6349-6352.

Jacobs, L. F., \& Spencer, W. D. (1994). Natural space-use patterns and hippocampal size in kangaroo rats. Brain Behavior Evolution, 44, 125-132.

Jeffery, K. J. (2018). The hippocampus: From memory, to map, to memory map. Trends in Neurosciences, 41, 64-66.

Johnson, Z. V., Walum, H., Xiao, Y., Riefkohl, P. C., \& Young, L. J. (2017). Oxytocin receptors modulate a social salience neural network in male prairie voles. Hormones and Behavior, 87, 16-24.

Jurek, B., \& Neumann, I. D. (2018). The oxytocin receptor: From intracellular signaling to behavior. Physiological Reviews, 98, 1805-1908.

Kilner, R. M., \& Langmore, N. E. (2011). Cuckoos versus hosts in insects and birds: Adaptations, counter-adaptations and outcomes. Biological Reviews of the Cambridge Philosophical Society, 86, 836-852.

Kitchen, D., Bergman, T., Cheney, D., Nicholson, J., \& Seyfarth, R. (2010). Comparing responses of four ungulate species to playbacks of baboon alarm calls. Animal Cognition, 13, 861-870. 
Knobloch, H. S., \& Grinevich, V. (2014). Evolution of oxytocin pathways in the brain of vertebrates. Frontiers in Behavioral Neuroscience, 8 , 31.

Langley, C. M. (1994). Spatial memory in the desert kangaroo rat (Dipodomys deserti). Journal of Comparative Psychology, 108, 3-14.

Leadbeater, E., \& Chittka, L. (2007). Social learning in insects: From miniature brains to consensus building. Current Biology, 17, R703-R713.

Lebreton, S., Borrero-Echeverry, F., Gonzalez, F., Solum, M., Wallin, E. A., Hedenström, E., Hansson, B. S., Gustavsson, A.-L., Bengtsson, M., Birgersson, G., Walker, W. B. III, Dweck, H. K. M., Becher, P. G., \& Witzgall, P. (2017). A Drosophila female pheromone elicits speciesspecific long-range attraction via an olfactory channel with dual specificity for sex and food. BMC Biology, 15, 88.

Lehmann, L., \& Keller, L. (2006). The evolution of cooperation and altruism: A general framework and a classification of models. Journal of Evolutionary Biology, 19, 1365-1376.

Lehtonen, T. K., McCrary, J. K., \& Meyer, A. (2010). Territorial aggression can be sensitive to the status of heterospecific intruders. Behavioural Processes, 84, 598-601.

Lehtonen, T. K., McCrary, J. K., \& Meyer, A. (2012). Introduced predator elicits deficient brood defence behaviour in a crater lake fish. PLoS One, 7, e30064.

Lehtonen, T. K., Sowersby, W., Gagnon, K., \& Wong, B. B. (2015). Cichlid fish use coloration as a cue to assess the threat status of heterospecific intruders. American Naturalist, 186, 547-552.

Lehtonen, T. K., Sowersby, W., \& Wong, B. B. (2015). Heterospecific aggression bias towards a rarer colour morph. Proceedings of the Royal Society of London B, 282, 20151551.

Lehtonen, T. K., Gagnon, K., Sowersby, W., \& Wong, B. B. (2016). Allopatry, competitor recognition and heterospecific aggression in crater lake cichlids. BMC Evolutionary Biology, 16, 3.

Libersat, F., Kaiser, M., \& Emanuel, S. (2018). Mind control: How parasites manipulate cognitive functions in their insect hosts. Frontiers in Psychology, 9, 572.

Lloyd, M. (1968). Self-regulation of adult numbers by cannibalism in two laboratory strains of four beetles (Tribolium castaneum). Ecology, 49, 245-259.

Long, K. D., Kennedy, G., Salbaum, J. M., \& Balaban, E. (2002). Auditory stimulus-induced changes in immediate-early gene expression related to an inborn perceptual predisposition. Journal of Comparative Physiology A, 188, 25-38.

Louder, M. I. M., Hauber, M. E., \& Balakrishnan, C. N. (2018). Early social experience alters transcriptomic responses to species-specific song stimuli in female songbirds. Behavioural Brain Research, 347, 69-76.

Louder, M. I. M., Lafayette, M., Louder, A. A., Uy, F. M. K., Balakrishnan, C. N., Yasukawa, K., \& Hauber, M. E. (2020). Shared transcriptional responses to con- and heterospecific behavioral antagonists in a wild songbird. Scientific Reports, 10, 4092.

Louder, M. I. M., Lawson, S., Lynch, K. S., Balakrishnan, C. N., \& Hauber, M. E. (2019). Neural mechanisms of auditory species recognition in birds. Biological Reviews, 94, 1619-1635.

Louder, M. I. M., Voss, H. U., Manna, T. J., Carryl, S. S., London, S. E., Balakrishnan, C. N., \& Hauber, M. E. (2016). Shared neural substrates for song discrimination in parental and parasitic songbirds. Neuroscience Letters, 622, 49-54.

Lukoschek, V., \& McCormick, M. I. (2000). A review of multi-species foraging associations in fishes and their ecological significance. In Proceedings of the 9th International Coral Reef Symposium (pp. 467474). Ministry of Environment, Indonesia; Indonesian Institute of Sciences, International Society for Reef Studies.

Lynch, K. S., Gaglio, A., Tyler, E., Coculo, J., Louder, M. I. M., \& Hauber, M. E. (2017). A neural basis for password-based species recognition in an avian brood parasite. Journal of Experimental Biology, 220, 2345-2353.
Magrath, R. D., \& Bennett, T. H. (2012). A micro-geography of fear: Learning to eavesdrop on alarm calls of neighbouring heterospecifics. Proceedings of the Royal Society of London B, 279, 902-909.

Magrath, R. D., Pitcher, B. J., \& Gardner, J. L. (2009). An avian eavesdropping network: Alarm signal reliability and heterospecific response. Behavioral Ecology, 20, 745-752.

Manica, A. (2002). Filial cannibalism in teleost fish. Biological Reviews, 77, 261-267.

Matsumoto, Y., Tateishi, T., Terada, R., Soyano, K., \& Takegaki, T. (2018). Filial cannibalism by male fish as an infanticide to restart courtship by self-regulating androgen levels. Current Biology, 28(2831-2836), e3.

May, D., \& Reboreda, J. C. (2005). Conspecific and heterospecific social learning in shiny cowbirds. Animal Behaviour, 70, 1087-1092.

McKaye, K. R. (1977). Competition for breeding sites between the cichlid fishes of Lake Jiloá, Nicaragua. Ecology, 58, 291-302.

Meier, J., Marques, D., Mwaiko, S., Wagner, C. E., Excoffier, L., \& Seehausen, O. (2017). Ancient hybridization fuels rapid cichlid fish adaptive radiations. Nature Communications, 8, 14363.

Meier, J. I., Stelkens, R. B., Joyce, D. A., Mwaiko, S., Phiri, N., Schliewen, U. K., Selz, O. M., Wagner, C. E., Katongo, C., \& Seehausen, O. (2019). The coincidence of ecological opportunity with hybridization explains rapid adaptive radiation in Lake Mweru cichlid fishes. Nature Communications, 10, 5391.

Meise, K., Franks, D. W., \& Bro-Jørgensen, J. (2019). Alarm communication networks as a driver of community structure in African savannah herbivores. Ecology Letters, 23, 293-304.

Melis, A. P., Hare, B., \& Tomasello, M. (2006). Chimpanzees recruit the best collaborators. Science, 311, 1297-1300.

Mendonça, R., Soares, M. C., Bshary, R., \& Oliveira, R. F. (2013). Arginine vasotocin neuronal phenotype and interspecific cooperative behaviour. Brain, Behavior and Evolution, 82, 166-176.

Moore, J. M., \& Woolley, S. M. N. (2019). Emergent tuning for learned vocalizations in auditory cortex. Nature Neuroscience, 22, 1469-1476.

Nagasawa, M., Mitsui, S., En, S., Ohtani, N., Ohta, M., Sakuma, Y., Onaka, T., Mogi, K., \& Kikusui, T. (2015). Oxytocin-gaze positive loop and the coevolution of human-dog bonds. Science, 348, 333-336.

Newman, S. W. (1999). The medial extended amygdala in male reproductive behavior a node in the mammalian social behavior network. Annals of the New York Academy of Sciences, 877, 242-257.

O'Connell, L. A., \& Hofmann, H. A. (2011). The vertebrate mesolimbic reward system and social behavior network: a comparative synthesis. Journal of Comparative Neurology, 519, 3599-3639.

O'Connell, L. A., \& Hofmann, H. A. (2012). Evolution of a vertebrate social decision-making network. Science, 336, 1154-1157.

O'Keefe, J. (1979). A review of the hippocampal place cells. Progress in Neurobiology, 13, 419-439.

Oliveira, R. F. (2004). Social modulation of androgens in vertebrates: Mechanisms and function. Advances in the Study of Behaviour, 34, 165-239.

Oliveira, R. F. (2009). Social behavior in context: hormonal modulation of behavioral plasticity and social competence. Integrative and Comparative Biology, 49, 423-440.

Omer, D. B., Maimon, S. R., Las, L., \& Ulanovsky, N. (2018). Social placecells in the bat hippocampus. Science, 359, 218-224.

Ord, T. J., King, L., \& Young, A. R. (2011). Contrasting theory with the empirical data of species recognition. Evolution, 65, 2572-2591.

Owen-Ashley, N. T., \& Butler, L. K. (2004). Androgens, interspecific competition and species replacement in hybridizing warblers. Proceedings of the Royal Society of London B, 271, Suppl. 6, S498-S500.

Paijmans, K. C., Booth, D. J., \& Wong, M. Y. L. (2019). Towards an ultimate explanation for mixed-species shoaling. Fish and Fisheries, 20, 921-933. 
Park, T., Mertz, D. B., Grodzinski, W., \& Prus, T. (1965). Cannibalistic predation in populations of flour beetles. Physiological Zoology, 38, 289-321.

Patriquin, K. J., Kohles, J. E., Page, R. A., \& Ratcliffe, J. M. (2018). Bats without borders: Predators learn novel prey cues from other predatory species. Science. Advances, 4, eaaq0579.

Peiman, K. S., \& Robinson, B. W. (2007). Heterospecific aggression and adaptive divergence in brook stickleback (Culaea inconstans). Evolution, 61, 1327-1338.

Peiman, K. S., \& Robinson, B. W. (2010). Ecology and evolution of resource-related heterospecific aggression. Quarterly Reviews in Biology, 85, 133-158.

Perdue, B. M., Snyder, R. J., Zhihe, Z., Marr, M. J., \& Maple, T. L. (2011). Sex differences in spatial ability: A test of the range size hypothesis in the order Carnivora. Biology Letters, 7, 380-383.

Pinto, A., Oates, J., Grutter, A., \& Bshary, R. (2011). Cleaner wrasses Labroides dimidiatus are more cooperative in the presence of an audience. Current Biology, 21, 1140-1144.

Polacik, M., Reichard, M., Smith, C., \& Blazek, R. (2019). Parasitic cuckoo catfish exploit parental responses to stray offspring. Philosophical Transactions of the Royal Society of London B, 374, 20180412.

Polis, G. A. (1981). The evolution and dynamics of intraspecific predation. Annual Reviews in Ecology and Systematics, 12, 225-251.

Pollock, M. S., Chivers, D. P., Mirza, R. S., \& Wisenden, B. D. (2003). Fathead minnows, Pimephales promelas, learn to recognize chemical alarm cues of introduced brook stickleback, Culaea inconstans. Environmental Biology of Fishes, 66, 313-319.

Raihani, N. J., Grutter, A. S., \& Bshary, R. (2010). Punishers benefit from third-party punishment in fish. Science, 327, 171.

Raihani, N. J., Pinto, A. I., Grutter, A. S., Wismer, S., \& Bshary, R. (2012). Male cleaner wrasses adjust punishment of female partners according to the stakes. Proceedings of the Royal Society of London B, $279,365-370$

Rainey, H. J., Zuberbühler, K., \& Slater, P. J. B. (2004). Hornbills can distinguish between primate alarm calls. Proceedings of the Royal Society of London B, 271, 755-759.

Reboreda, J. C., Clayton, N. S., \& Kacelnik, A. (1996). Species and sex differences in hippocampus size in parasitic and non-parasitic cowbirds. NeuroReport, 7, 505-508.

Rogers-Carter, M. M., \& Christianson, J. P. (2019). An insular view of the social decision-making network. Neuroscience and Biobehavioral Reviews, 103, 119-132.

Romero, T., Nagasawa, M., Mogi, K., Hasegawa, T., \& Kikusui, T. (2014). Oxytocin promotes social bonding in dogs. Proceedings of the National Academy of Sciences USA, 111, 9085-9090.

Ros, A. F. H., Vullioud, P., Bruintjes, R., Vallat, A., \& Bshary, R. (2014). Intra- and interspecific challenges modulate cortisol but not androgen levels in a year-round territorial damselfish. Journal of Experimental Biology, 217, 1768-1774.

Rossi, S., \& Snyder, M. J. (2001). Competition for space among sessile marine invertebrates: changes in HSP70 expression in two Pacific cnidarians. Biological Bulletin, 201, 385-393.

Russ, J. M., Jones, G., Mackie, I. J., \& Racey, P. A. (2004). Interspecific responses to distress calls in bats (Chiroptera: Vespertilionidae) A function for convergence in call design? Animal Behaviour, 67, 1005-1014.

Ryan, M. J., \& Rand, A. S. (1995). Female responses to ancestral advertisement calls in the túngara frog. Science, 269, 390-392.

Sabo, J. L., \& Pauley, G. B. (1997). Competition between streamdwelling cutthroat trout (Oncorhynchus clarki) and coho salmon (Oncorhynchus kisutch): Effects of relative size and population origin. Canadian Journal of Fisheries and Aquatic Sciences, 54, 2609-2617.

Sato, T. (1986). A brood parasitic catfish of mouthbrooding cichlid fishes in Lake Tanganyika. Nature, 323, 58-59.
Schlupp, I. (2005). The evolutionary ecology of gynogenesis. Annual Review of Ecology, Evolution, and Systematics, 36, 399-417.

Sclupp, I., Marler, C., \& Ryan, M. J. (1994). Benefit to male Sailfin mollies of mating with heterospecific females. Science, 263, 373-374.

Schmitt, M. H., Stears, K., Wilmers, C. C., \& Shrader, A. M. (2014). Determining the relative importance of dilution and detection for zebra foraging in mixed species herds. Animal Behaviour, 96, 151-158.

Seehausen, O., \& van Alphen, J. J. M. (1998). The effect of male coloration on female mate choice in closely related Lake Victoria cichlids (Haplochromis nyererei complex). Behavioral Ecology and Sociobiology, 42, 1-8.

Seppänen, T., \& Forsman, J. T. (2007). Interspecific social learning: Novel preference can be acquired from a competing species. Current Biology, 17, 1248-1252.

Sherry, D. F., Forbes, M. R., Khurgel, M., \& Ivy, G. O. (1993). Females have a larger hippocampus than males in the brood-parasitic brownheaded cowbird. Proceedings of the National Academy of Sciences USA, 90, 7839-7843.

Soares, M. C., Bshary, R., Mendonça, R., Grutter, A. S., \& Oliveira, R. F. (2012). Arginine vasotocin regulation of interspecific cooperative behaviour in a cleaner fish. PLoS One, 7, e39583.

Soma, K. K. (2006). Testosterone and aggression: Berthold, birds and beyond. Journal of Neuroendocrinology, 18, 543-551.

Sonleitner, F. J., \& Guthrie, P. J. (1991). Factors affecting oviposition rate in the flour beetle Tribolium castaneum and the origin of the population regulating mechanism. Researches in Population Ecology, 33, 1-12.

Sorenson, M. D., \& Payne, R. B. (2005). A molecular genetic analysis of the cuckoo phylogeny. In R. B. Payne (Ed.), The Cuckoos (pp. 68-94). Oxford University Press.

Spence, J. R., Cárcamo, H. A., \& Carcamo, H. A. (1991). Effects of cannibalism and intraguild predation on pondskaters (Gerridae). Oikos, $62,333-341$

Sridhar, H., Jordán, F., \& Shanker, K. (2013). Species importance in a heterospecific foraging association network. Oikos, 122 1325-1334.

Stears, K., Schmitt, M. H., Wilmers, C. C., \& Shrader, A. M. (2020). Mixedspecies herding levels the landscape of fear. Proceedings of the Royal Society B, 287, 20192555

Stensland, E., Angerbjorn, A., \& Berggren, P. (2003). Mixed species groups in mammals. Mammalogy Reviews, 33, 205-223.

Stevens, L. (1989). The genetics and evolution of cannibalism in flour beetles (genus Tribolium). Evolution, 43, 169-179.

Stevens, M. (2013). Bird brood parasitism. Current Biology, 23, R909-R913.

Svardal, H., Quah, F. X., Malinsky, M., Ngatunga, B. P., Miska, E. A., Salzburger, W., Genner, M. J., Turner, G. F., \& Durbin, R. (2020). Ancestral hybridization facilitated species diversification in the lake malawi cichlid fish adaptive radiation. Molecular Biology and Evolution, 37, 1100-1113.

Székely, T., Moore, A. J., \& Komdeur, J. (2010). Social behaviour: Genes, ecology and evolution. Cambridge University Press.

Taborsky, B., \& Oliveira, R. F. (2012). Social competence: An evolutionary approach. Trends in Ecology and Evolution, 27, 679-688.

Tannerfeldt, M., Elmhagen, B., \& Angerbjörn, A. (2002). Exclusion by interference competition? The relationship between red and arctic foxes. Oecologia, 132, 213-220.

Teles, M. C., Almeida, O., Lopes, J. S., \& Oliveira, R. F. (2015). Social interactions elicit rapid shifts in functional connectivity in the social decision-making network of zebrafish. Proceedings of the Royal Society of London B, 282, 20151099.

Templeton, C. N., Greene, E., \& Davis, K. (2005). Allometry of alarm calls: Black-capped chickadees encode information about predator size. Science, 308, 1934-1937. 
Terborgh, J. (1990). Mixed flocks and polyspecific associations: costs and benefits of mixed groups to birds and monkeys. American Journal of Primatology, 21, 87-100.

Toledo, L. F., Martins, I. A., Bruschi, D. P., Passos, M. A., Alexandre, C., \& Haddad, C. F. B. (2015). The anuran calling repertoire in the light of social context. Acta Ethologica, 18, 87-99.

Todorov, O. S., Weisbecker, V., Gilissen, E., Zilles, K., \& de Sousa, A. A. (2019). Primate hippocampus size and organization are predicted by sociality but not diet. Proceedings of the Royal Society of London B, 286, 20191712.

Triki, Z., Wismer, S., Rey, O., Binning, S. A., Levorato, E., \& Bshary, R. (2019). Biological market effects predict cleaner fish strategic sophistication. Behavioral Ecology, 30, 1548-1557.

Triki, Z., Emery, Y., Teles, M. C., Oliveira, R. F., \& Bshary, R. (2020). Brain morphology predicts social intelligence in wild cleaner fish. Nature Communications, 11, 6423.

Truskanov, N., Emery, Y., \& Bshary, R. (2020). Juvenile cleaner fish can socially learn the consequences of cheating. Nature Communications, 11, 1-9.

Tschinkel, W. R. (1993). Resource allocation, brood production and cannibalism during colony founding in the fire ant, Solenopsis invicta. Behavioral Ecology and Sociobiology, 33, 209-233.

Van Buskirk, J. (1989). Density-dependent cannibalism in larval dragonflies. Ecology, 70, 1442-1449.

Vail, A. L., Manica, A., \& Bshary, R. (2013). Referential gestures in fish collaborative hunting. Nature Communications, 4, 1-7.

Vail, A. L., Manica, A., \& Bshary, R. (2014). Fish choose appropriately when and with whom to collaborate. Current Biology, 24, R791-R793.

Vitousek, M. N., Adelman, J. S., Gregory, N. C., \& Clair, J. J. H. S. (2007). Heterospecific alarm call recognition in a non-vocal reptile. Biology Letters, 3, 632-634.

Vullioud, P., Bshary, R., \& Ros, A. F. H. (2013). Intra- and interspecific aggression do not modulate androgen levels in dusky gregories, yet male aggression is reduced by an androgen blocker. Hormones and Behavior, 64, 430-438.

Ward, A. J. W., \& Webster, M. (2016). Sociality: The behaviour of group living animals. Springer International Publishing.

Whaling, C. S., Solis, M. M., Doupe, A. J., Soha, J. A., \& Marler, P. (1997). Acoustic and neural bases for innate recognition of song. Proceedings of the National Academy of Sciences, 94, 12694-12698.

Whiting, M. J., \& Greeff, J. M. (1999). Use of heterospecific cues by the lizard Platysaurus broadleyi for food location. Behavioral Ecology and Sociobiology, 45, 420-423.

Williams, T. H., \& Mendelson, T. C. (2011). Female preference for male coloration may explain behavioural isolation in sympatric darters. Animal Behaviour, 82, 683-689.

Wingfield, J. C. (1994). Regulation of territorial behavior in the sedentary song sparrow. Melospiza melodia morphna. Hormones and Behavior, 28(1), 1-15.

Wingfield, J. C., Hegner, R. E., Dufty, A. M. Jr, \& Ball, G. F. (1990). The "challenge hypothesis": theoretical implications for patterns of testosterone secretion, mating systems, and breeding strategies. American Naturalist, 136, 829-846.

Wagner, J. D., \& Wise, D. H. (1996). Cannibalism regulates densities of young wolf spiders: evidence from field and laboratory experiments. Ecology, 77, 639-652.

West, S. A., Griffin, A. S., \& Gardner, A. (2007). Evolutionary explanations for cooperation. Current Biology, 17, R661-R672.

How to cite this article: Oliveira RF, Bshary R. Expanding the concept of social behavior to interspecific interactions.

Ethology. 2021;127:758-773. https://doi.org/10.1111/

eth.13194 